This document is confidential and is proprietary to the American Chemical Society and its authors. Do not copy or disclose without written permission. If you have received this item in error, notify the sender and delete all copies.

\title{
Bifunctionalized redox-responsive layers prepared from a thiolactone copolymer
}

\begin{tabular}{|r|l|}
\hline Journal: & Langmuir \\
\hline Manuscript ID & Draft \\
\hline Manuscript Type: & Article \\
\hline Date Submitted by the Author: & n/a \\
\hline Complete List of Authors: & $\begin{array}{l}\text { Chattaway, Claire; Universite catholique de Louvain Ecole Polytechnique de } \\
\text { Louvain } \\
\text { Belbekhouche, Sabrina; Institute of Condensed Matter and Nanosciences, } \\
\text { Bio and Soft Matter Group, Universite catholique de Louvain, } \\
\text { Du Prez, Filip; Ghent University, Organic and Macromolecular Chemistry } \\
\text { Glinel, Karine; Université catholique de Louvain, Institute of Condensed } \\
\text { Matter and Nanosciences } \\
\text { Demoustier-Champagne, Sophie; Université catholique de Louvain, } \\
\text { Institute of Condensed Matter and Nanosciences - Bio \& Soft Matter } \\
\text { (IMCN/BSMA) }\end{array}$ \\
\hline
\end{tabular}

\section{SCHOLARONE}

Manuscripts 


\title{
Bifunctionalized redox-responsive layers
}

\section{prepared from a thiolactone copolymer}

\author{
Claire Chattaway,,$^{\dagger}$ Sabrina Belbekhouche,,$^{\dagger}$ Filip E. Du Prez, ${ }^{+}$Karine Glinel, ${ }^{\dagger}, *$ Sophie \\ Demoustier-Champagne $e^{\dagger, *}$
}

$†$ Institute of Condensed Matter \& Nanosciences (Bio \& Soft Matter), Université catholique de Louvain, Croix du Sud 1, box L7.04.02, B-1348 Louvain-la-Neuve, Belgium

\$ Polymer Chemistry Research Group, Centre of Macromolecular Chemistry (CMaC), Department of Organic and Macromolecular Chemistry, Ghent University, Krijgslaan 281 S4, B9000 Ghent, Belgium

\begin{abstract}
Keywords. Gold surface modification; thiolactone aminolysis; dual functionality; disulfide link, redox-responsive layer.
\end{abstract}




\begin{abstract}
The development of multifunctional surfaces is of general interest for the fabrication of biomedical, catalytic, microfluidic or biosensing devices. Herein, we report on the preparation of copolymer layers immobilized on gold surface and showing both free thiol and amino groups. These layers are produced by aminolysis of a thiolactone-based copolymer in the presence of a diamine, according to a one-step procedure. The free thiol and amino groups present in the modified copolymer layers can be successfully functionalized with respectively thiolated and carboxylic derivatives, in order to produce bifunctionalized surfaces. In addition, we show that the grafted thiolated derivative can be released by cleavage of the disulfide bond under mild reducing conditions. On the other hand, a side crosslinking reaction occurring during the grafting process and resulting in the formation of copolymer aggregates on the metal surface is evidenced. The methodology developed for the preparation of these bifunctionalized redoxresponsive layers should be advantageously used to produce bioactive surfaces with drug loading/release properties.
\end{abstract}

\title{
Introduction
}

The development of coatings containing reactive chemical groups allowing for the subsequent immobilization of various compounds, has been gaining an increasing attention because of their potential use to modify surfaces of various devices involved in biomedical, catalytic, microfluidic or biosensing applications. ${ }^{1-4}$ In the field of catalysis for instance, enzymes, chemical ligands or even substrates are grafted on surfaces enabling to reuse the catalyst for several batches, improving therefore the environmental and the economic impacts of the 
process. ${ }^{4-7}$ Regarding biomaterials, surfaces grafted with bioadhesive peptides improving cell adhesion, ${ }^{8,9}$ signal proteins directing differenciation, ${ }^{10}$ or even antibacterial peptides, ${ }^{11-13}$ are highly interesting to improve biocompatibility. Moreover, joining different chemically reactive groups on the same surface enables the possibility of preparing dual- or multi-functionalized materials. For instance, interfaces of implantable materials that simultaneously promote mammalian cells while inhibiting bacterial adhesion have been developed. ${ }^{14,15}$ In catalytic applications, the efficiency of the reaction can be increased by immobilizing two or more active species or enzymes onto the reactive surface. ${ }^{16,17}$ Among the many reported approaches for tailoring the surface properties of a material, ${ }^{18-20}$ the sorption of self-assembled monolayers (SAMs) on metals and metal oxides appears as one of the most simple and versatile method $^{1,19,21,22}$ allowing to bring a wide variety of chemical functions on the surface such as carboxylic acid, amine, alkane, alcohol, azide, etc. ${ }^{23}$ Moreover, mixed monolayers can be prepared by co-grafting of alkanethiolates or silanes bearing different terminal chemical functions ${ }^{1,24-26}$ that can be further modified with compounds of interest, such as proteins, peptides, DNA or small active molecules. ${ }^{21,23,27}$ These multifunctional platforms were shown to be useful for diverse applications such as biosensing, catalysis or development of model biological surfaces to control cellular processes or study the ligand-protein interaction.,17,23 Research and commercial use of gold coated surfaces and nanoparticles has rapidly expanded in many fields, including biodetection, biomedicine, ${ }^{1,28}$ etc. SAMs of alkanethiols are probably the most widely studied systems to functionalize gold surfaces. ${ }^{1,29,30}$ However, thiol-based SAMs suffer from several drawbacks. Indeed, alkylthiolates grafted on metallic surface are eventually oxidized to sulfonates $\left(\mathrm{SO}_{2}{ }^{2-}, \mathrm{SO}_{3}{ }^{2-}\right)$ and released from the surface. ${ }^{21,31}$ Moreover, exchange can occur between thiol molecules grafted onto the gold surface and alkylthiols present in the 
surrounding solution, contributing to a poor control of the chemical functionality on the surface. ${ }^{31-33}$ An alternative way to functionalize gold surfaces is based on the use of polythiols. Such polymers can be grafted onto a gold surface through several anchoring points thanks to the presence of multiple thiol groups, which contributes to an increased stability of the elaborated layer. $^{34,35}$ However, polythiols are prone to oxidation under ambient atmosphere which considerably limits their manipulation. To overcome this drawback, Du Prez and co-workers ${ }^{36-43}$ have recently developed copolymers incorporating thiolactone as a latent thiol functionality. By opening thiolactone cycles using a strong nucleophile such as an amine and/or thiol groups are liberated and are available to immobilize compounds of interest through a cleavable disulfide bond or via 'click chemistry'.

Recently, we reported the use of these thiolactone-based copolymers as precursors to produce stable polythiol layers onto gold surfaces, according to a one-step process. For this, a gold surface was simply immersed in a copolymer solution in the presence of an amine derivative such as ethanolamine. ${ }^{44}$ It was shown that a part of the thiol groups released from the thiolactone rings during the aminolysis reaction was involved in the formation of stable sulfur-gold bonds between the copolymer chains and the gold surface while another fraction remained free and was further used to immobilize a thiolated derivative of interest through a cleavable disulfide bond. The preparation of redox-responsive copolymer layers leading to the grafting and subsequent release of a thiolated derivative under reducing and oxidizing conditions, respectively, were successfully demonstrated.

In the present work, we report on the production of bifunctionalized gold surfaces, using a thiolactone-based copolymer as starting material (Scheme 1). The most appealing feature of the surface functionalization strategy reported herein (Scheme 2) is the simultaneous immobilization 
of in-situ generated polythiols onto gold substrate and the creation of two different types of functional groups $\left(\mathrm{NH}_{2}\right.$ and $\left.\mathrm{SH}\right)$ on the copolymer backbone, allowing for the versatile preparation of diverse bifunctionalized redox-responsive surfaces.

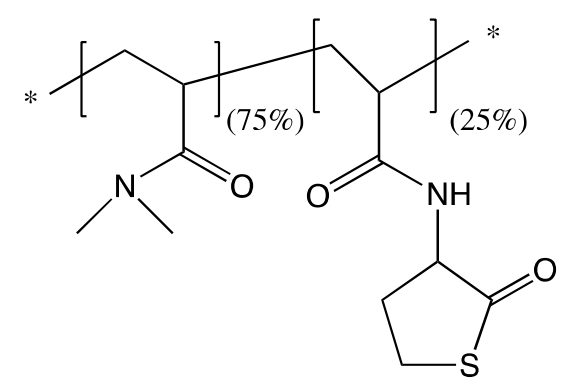

Scheme 1. Chemical structure of the thiolactone-based copolymer, P(DMA-co-TlaAm) used in this work.

For this, the surface functionalization was performed in the presence of a diamine derivative, instead of a monoamine, in order to produce layers showing both free thiol and amine groups (Scheme 2, step 1). While the free thiol groups can be used to immobilize a releasable compound of interest through a cleavable disulfide link, the amino groups can prior or further react with another compound containing a carboxylic acid group thanks to the EDC/sulfo-NHS coupling technique (Scheme 2, step 2). First, the use of a diamine and the influence of the copolymer concentration on the formation of the copolymer layer were studied. In a second step, the modification of amine and thiol groups present in the copolymer layer was investigated separately (Scheme 3, steps 1 and 1'), prior to the modification of both amine and thiol functions (Scheme 3, steps $1+2$ or $1^{\prime}+2$ '). 


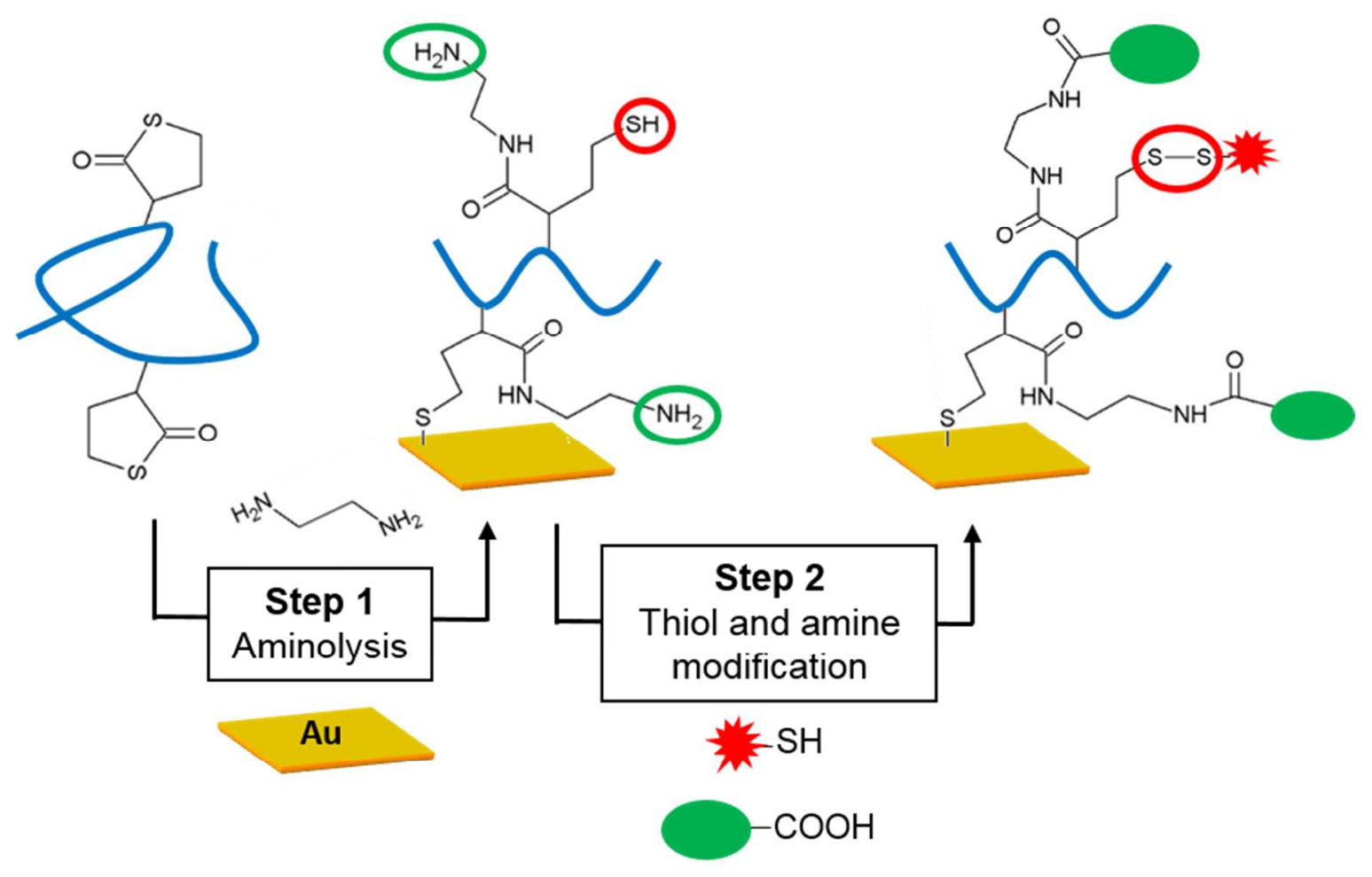

Scheme 2. General approach to fabricate bifunctional layers on gold surfaces. The thiolactone moieties of the copolymer are first opened in presence of a diamine derivative, generating amine and thiol groups onto the copolymer chain (step 1); a part of the released thiol groups is attaching onto the gold surface to form the copolymer layer while the rest of thiol and amine groups are available for subsequent graftings (step 2). While free amine groups are modified with carboxylic acid bearing molecules, the free thiol groups, on the other hand, react with a thiolated derivative through the formation of a cleavable disulfide bond that confers redox-responsive properties to the copolymer layer. 


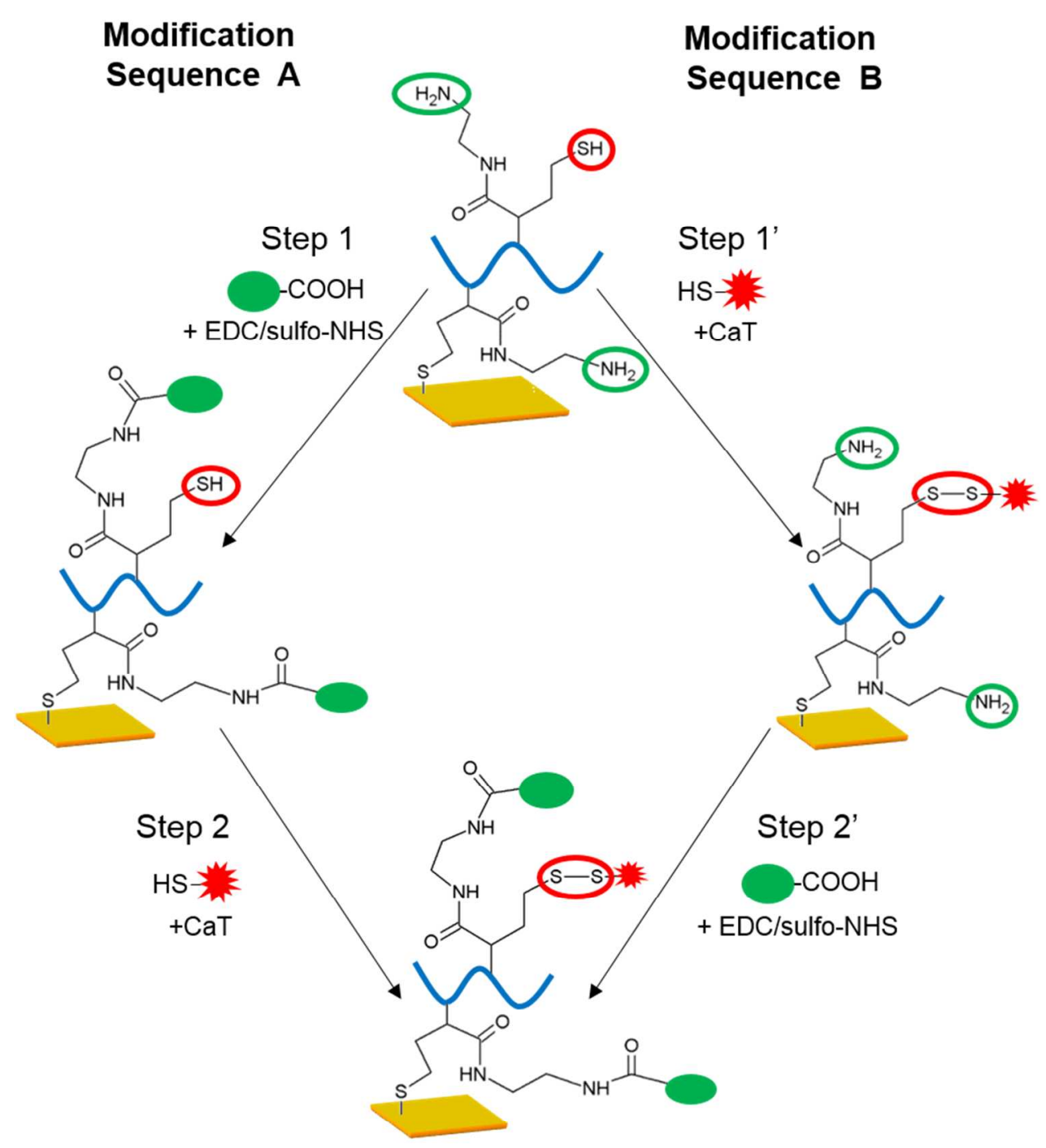

Bifunctionalized surface

Scheme 3. The two different sequences of surface modification used in this study to prepare bifunctionalized copolymer layers. Sequence A: Amine groups (step 1) then thiol groups (step 2) of the copolymer layer are modified. Sequence B: thiol groups (step 1') then amine groups (step 2') are modified. 


\section{Experimental Section}

Materials. A statistical copolymer based on $N, N$-dimethyacrylamide (DMA) and thiolactone acrylamide (TlaAm) was synthesized by RAFT polymerization according to a methodology previously described. ${ }^{42}$ This copolymer P(DMA-co-TlAm) had an apparent average molar mass of 32000 g.mol ${ }^{-1}$ with a dispersity (Đ) of 1.1, as measured by size exclusion chromatography (SEC) and contained $25 \%$ of TlaAm units as determined by elemental analysis. Ethanolamine (Sigma-Aldrich, 99\%), ethylenediamine (Sigma-Aldrich, 99+\%), propylamine (Acros Organics, $98 \%$ ), FITC-labeled H-RGDK(FITC)-OH peptide $\quad\left(\right.$ RGD-FITC, $\left.\quad \mathrm{M}_{\mathrm{W}}=863.91{\mathrm{~g} . \mathrm{mol}^{-1}}^{-}\right)$ (Genecust, 99+\%), 4,4,4-trifluorobutyric acid (Sigma-Aldrich, 97\%), CSIINFEKL peptide (OVA peptide, $\mathrm{M}_{\mathrm{W}}=1066.28 \mathrm{~g} \cdot \mathrm{mol}^{-1}$ ) (Genecust, 96+\%), glycylglycine (Sigma-Aldrich, 99+\%), $N$-hydroxysulfosuccinimide sodium salt (sulfo-NHS) (Sigma-Aldrich, 98+ \%), $N$-(3dimethylaminopropyl)- $N$ '-ethylcarbodiimide hydrochloride (EDC) (Sigma-Aldrich, 98+ \%), $N$ chloro-p-toluenesulfonamide sodium salt trihydrate (CaT) (Sigma-Aldrich, $98 \%$ ), threo-1,4dimercapto-2,3-butanediol (DTT) (Sigma-Aldrich, 99+\%), L-glutathione reduced (SigmaAldrich, $98 \%$ ), poly(ethylene glycol)methyl ether thiol (PEG-SH) (Sigma Aldrich, $\mathrm{M}_{\mathrm{n}}=2000 \mathrm{~g} \cdot \mathrm{mol}^{-1}$ ), rhodamine B-poly(ethylene glycol)-thiol (Rhod B-PEG-SH) (Interchim, $\mathrm{M}_{\mathrm{W}}=3400 \mathrm{~g} \cdot \mathrm{mol}^{-1}$ ), potassium hexacyanoferrate (III) (Sigma-Aldrich, 99+\%), potassium hexacyanoferrate (II) trihydrate (Sigma-Aldrich, 99.5+ \%), potassium chloride (KCl) (SigmaAldrich), 4-(2-hydroxyethyl)-1-piperazineethanesulfonic acid (HEPES) (Sigma-Aldrich, 99.5+\%), 2-(N-morpholino)ethanesulfonic acid (MES) (Sigma-Aldrich, 99.5+\%), chloroform $\left(\mathrm{CHCl}_{3}\right)$ (Sigma-Aldrich, 99.5+\%, anhydrous), ethanol (VWR, HPLC grade), hydrogen peroxide (Sigma-Aldrich, $30 \%$ ), sulfuric acid (Sigma-Aldrich) were used as received. Milli-Q water (resistivity $18.2 \mathrm{M} \Omega . \mathrm{cm}$ ) was obtained from a Merck Millipore system (Milli-Q ${ }^{\circledR}$ 
Reference). Gold surfaces were fabricated in a clean room environment (Winfab platform, Université catholique de Louvain) by evaporating a $100 \mathrm{~nm}$-thick layer of gold on 1 x $1 \mathrm{~cm}^{2}$ silicon wafers (100) precoated with a $5 \mathrm{~nm}$-thick layer of chromium. All glassware used for surface modification was cleaned using piranha solution $(1: 2 \mathrm{v} / \mathrm{v}$ mixture of hydrogen peroxide (30\%) and sulfuric acid; caution: piranha solution is extremely reactive and should be handled carefully).

\section{Grafting of P(DMA-co-TlaAm) copolymer onto gold surfaces in presence of amine}

derivatives. $1 \times 1 \mathrm{~cm}^{2}$ gold surfaces were first cleaned with water and ethanol, then dried with a stream of $\mathrm{N}_{2}$. This process was repeated three times. Afterwards, surfaces were treated in an UV/ozone chamber (UVO-Cleaner, Jelight) for $20 \mathrm{~min}$, rinsed with ethanol and dried with a stream of $\mathrm{N}_{2}$. The grafting of P(DMA-co-TlaAm) copolymer onto gold surfaces was performed in the presence of either ethanolamine or ethylenediamine. Briefly, $5 \mathrm{~mL}$ of 2 or $0.2 \mathrm{mg} \cdot \mathrm{mL}^{-1}$ copolymer solution in chloroform was placed in a glass vial. A solution of the selected amine derivative was added to get 2 eq. or 10 eq. of TlaAm units for ethanolamine and ethylenediamine in the mixture, respectively. This mixture was stirred for $30 \mathrm{~s}$ and a freshly cleaned gold surface was rapidly added in the vial. After a contact time of $2 \mathrm{~h}$, the surface was thoroughly rinsed with chloroform, ethanol, and Milli-Q water then dried with a stream of $\mathrm{N}_{2}$. To avoid the formation of disulfide bonds between the thiol groups present in the copolymer layer, all the modified surfaces were treated with a DTT solution ( $2 \mathrm{mM}$, in $10 \mathrm{mM}$ HEPES, $\mathrm{pH} 7.2)$ for $10 \mathrm{~min}$, then rinsed with water and ethanol and eventually dried. 


\section{Modification of the amine pendent groups of copolymer layers by a carboxylic acid} derivative. A gold surface freshly modified with $\mathrm{P}(\mathrm{DMA}-\mathrm{co}-\mathrm{TlaAm})$ copolymer in the presence of ethylenediamine was sealed into a schlenk tube, which was then carefully degassed (i.e. 3 vacuum/Ar filling cycles). At the same time, EDC (16 mM), sulfo-NHS (30 mM) and the carboxylic derivative to be grafted onto the copolymer layer, i.e. glycylglycine or 4,4,4trifluorobutyric acid or RGD-FITC $(30 \mathrm{mM})$, were allowed to react together in degassed MES buffer ( $0.1 \mathrm{M}, \mathrm{pH}$ 6) for $15 \mathrm{~min}$, to get the corresponding activated ester derivative. Afterwards, $1 \mathrm{~mL}$ of solution of activated glycylglycine or 4,4,4,-trifluorobutyric acid was rapidly added into the schlenk tube with $4 \mathrm{~mL}$ of degassed PBS buffer $(0.1 \mathrm{M}, \mathrm{pH} 8)$. In the case of the RGD peptide grafting, $200 \mu \mathrm{L}$ of solution of activated RGD-FITC and $0.8 \mathrm{~mL}$ of degassed PBS buffer were added in the tube. In all cases, the grafting reaction was carried out for $1 \mathrm{~h}$. To estimate the unspecific adsorption of the carboxylic derivatives onto copolymer layers, surfaces grafted with the copolymer were treated in the same conditions but without activation by EDC/sulfo-NHS.

\section{Grafting and release of thiolated compounds on the pendent thiol groups of copolymer} layers. Fluorescent Rhod B-PEG-SH, PEG-SH or OVA peptide were immobilized onto the free thiol groups of $\mathrm{P}(\mathrm{DMA}-\mathrm{co}-\mathrm{TlaAm})$ layers prepared in the presence of ethylenediamine, through the formation of disulfide bonds. For this, a $1 \times 1 \mathrm{~cm}^{2}$ gold surface freshly modified with the thiolactone copolymer was placed in a $2 \mathrm{~cm}$-diameter petri dish. The thiolated compound to be grafted on the free thiol groups of the copolymer layer was dissolved in $1 \mathrm{~mL}$ of MES buffer (10 mM, pH 6) at a concentration of $0.3 \mathrm{mM}$ and $100 \mu \mathrm{L}$ of this solution was deposited onto the gold surface. Then, $1 \mathrm{~mL}$ of a $2 \mathrm{mM}$ CaT solution in MES buffer (10 mM, pH 6) was added. After a contact time of $2 \mathrm{~min}$, the surface was thoroughly rinsed with ethanol then Milli-Q water. 
To release the grafted thiolated compound from the copolymer layer, the surface was subsequently treated under reductive conditions. For this, the surface was placed for $20 \mathrm{~min}$ either in a DTT $(2 \mathrm{mM})$ solution or a L-glutathione $(10 \mathrm{mM})$ solution. Both solutions were buffered with HEPES (10 mM) at pH 7.2.

\section{Characterization techniques}

X-ray photoelectron spectroscopy (XPS). The XPS measurements were performed on a SSX 100/206 photoelectron spectrometer from Surface Science Instruments (USA) equipped with a monochromatized micro focused $\mathrm{Al} \mathrm{X}$-ray source (powered at $20 \mathrm{~mA}$ and $10 \mathrm{kV}$ ). The pressure in the analysis chamber was around $10^{-6} \mathrm{~Pa}$. The angle between the surface normal and the axis of the analyser lens was $55^{\circ}$. The analyzed area was approximately $1.4 \mathrm{~mm}^{2}$ and the pass energy was set at $150 \mathrm{eV}$. In these conditions, the full width at half maximum (FWHM) of the $\mathrm{Au} 4 \mathrm{f}_{7 / 2}$ peak of a clean gold standard sample was about $1.6 \mathrm{eV}$. A flood gun set at $8 \mathrm{eV}$ and a $\mathrm{Ni}$ grid placed at $3 \mathrm{~mm}$ above the sample surface were used for charge stabilisation. A survey spectrum was first acquired with a step of $1 \mathrm{eV}$. Then the following sequence of narrow spectra was recorded with a step of $0.1 \mathrm{eV}: \mathrm{C} 1 \mathrm{~s}, \mathrm{O} 1 \mathrm{~s}, \mathrm{~N} 1 \mathrm{~s}, \mathrm{~F} 1 \mathrm{~s}$ (whenever a fluorine-containing sample was used), $\mathrm{S} 2 \mathrm{p}, \mathrm{Au} 4 \mathrm{f}$ peaks and $\mathrm{C} 1 \mathrm{~s}$ again to check the stability of charge compensation with time. The $\mathrm{C}-(\mathrm{C}, \mathrm{H})$ component of the $\mathrm{C} 1 \mathrm{~s}$ peak has been fixed to $284.8 \mathrm{eV}$ to set the binding energy scale. Data treatment was performed with the CasaXPS program (Casa Software Ltd, UK). The spectra were decomposed with the least squares fitting routine provided by the software using a Gaussian/Lorentzian (85/15) product function and after subtraction of a nonlinear baseline. Molar fractions were calculated using peak areas measured after linear background subtraction and normalized on the basis of the acquisition parameters and sensitivity and transmission factors provided by the manufacturer. 
Electrochemical impedance spectroscopy (EIS). EIS characterization of the grafted layers was performed with a CHInstrument potentiostat 660B. The measurements were carried out at room temperature in a one-compartment Teflon cell equipped with a platinum counter electrode, an $\mathrm{Ag} / \mathrm{AgCl}$ reference electrode and the modified gold surface as a working electrode. The barrier properties of the grafted layers were evaluated by measuring the electron transfer reaction on the modified surface using a potassium ferrocyanide redox probe. The electrolytic solution contained equal concentrations of both oxidized and reduced forms of the redox couple namely, $1 \mathrm{mM}$ potassium ferrocyanide (II) $\left(\mathrm{K}_{4} \mathrm{Fe}(\mathrm{CN})_{6}\right)$ and (III) $\left(\mathrm{K}_{3} \mathrm{Fe}(\mathrm{CN})_{6}\right)$ solubilized in $0.1 \mathrm{M} \mathrm{KCl}$. All electrolyte solutions were purged with $\mathrm{N}_{2}$ for at least 10 min prior to measurements.

EIS measurements were performed at the open circuit potential with a sinusoidal voltage perturbation amplitude of $10 \mathrm{mV}$ in the frequency range from $1 \times 10^{-1}$ to $1 \times 10^{5} \mathrm{~Hz}$. The Nyquist plots obtained were fitted by a Randles equivalent circuit to estimate the charge transfer resistance $\left(\mathrm{R}_{\mathrm{ct}}\right)$. This circuit consists of a resistance element corresponding to the bulk solution in series with a parallel combination of an element of constant phase and Faradaic impedance, which is related to $\mathrm{R}_{\mathrm{ct}}$ and Warburg impedance representing the interfacial electron transfer resistance and the diffusion of the redox probe in solution, respectively. ${ }^{45} \mathrm{R}_{\mathrm{ct}}$ can also be obtained from the diameter of the high frequency semi-circle. ${ }^{46}$ The variation of $\mathrm{R}_{\mathrm{ct}}$ can be related to the gold surface coverage by the following equation. ${ }^{47}$

$$
\text { Surface coverage }=1-\frac{\mathrm{R}_{\mathrm{ct}}{ }^{0}}{\mathrm{R}_{\mathrm{ct}}}
$$

Where $\mathrm{R}_{\mathrm{ct}}{ }^{0}$ and $\mathrm{R}_{\mathrm{ct}}$ correspond to the charge transfer of the bare gold surface and the modified surface, respectively. 
Atomic force microscopy (AFM). AFM images were recorded in TappingTM mode (in light tapping regime) with a Bruker Nanoscope V device equipped with a PPP NCHR Nano Sensor tip. They were then analyzed using Nanoscope Analysis 1.8 software (Bruker). Briefly, recorded images were flattened by a $1^{\text {st }}$ order polynomial to remove the tilt. The average roughness of the recorded images was evaluated from $5 \times 5 \mu \mathrm{m}^{2}$ images.

Epifluorescence microscopy. The copolymer layers grafted with the fluorescent Rhod B-PEG-SH or RGD-FITC derivatives were observed with an optical inverted epifluorescence IX71 microscope (Olympus, Japan) equipped with a CCD camera, a fluorescence illuminator and various filter units. Images were recorded at $10 \mathrm{x}$ magnification and processed using the Cell Sens Dimension 1.7 software (Olympus, Japan). Scratches was deliberately made on the modified surfaces to compare the fluorescence resulting from the grafted copolymer layer with the background. Images were then analyzed with IGOR Pro software (version 6.22A, Wavemetrics, Inc.) according to the procedure described before ${ }^{12}$ to evaluate the fluorescence intensity.

High performance liquid chromatography-mass spectrometry (HPLC-MS). A LC system by ThermoFisher Products (San Jose, CA, USA) equipped with an Accela 1250 pump and an Accela Autosampler, was used to quantify the amount of OVA peptide released from copolymer layers under DTT treatment. For this purpose, surfaces modified with a copolymer layer grafted with OVA peptide were put in contact with $1 \mathrm{~mL}$ of reductive DTT solution (2 $\mathrm{mM}$ of DTT in $10 \mathrm{mM}$ HEPES, $\mathrm{pH}$ 7.2). This solution was further collected to determine the amount of released compound by HPLC-MS. Briefly, separation of OVA peptide was performed on a C18 Alltima column using a linear gradient from $97 \%$ of solution $\mathrm{A}\left(\mathrm{H}_{2} \mathrm{O}, 1 \% \mathrm{CH}_{3} \mathrm{CN}\right.$ and $\left.0.1 \% \mathrm{HCOOH}\right)$ 
and $3 \%$ of solution $\mathrm{B}\left(\mathrm{CH}_{3} \mathrm{CN}\right)$, for 3 minutes to $10 \%$ solution $\mathrm{A}$ and $90 \%$ of solution $\mathrm{B}$ for 28 min. The flow rate was $0.2 \mathrm{~mL} \cdot \mathrm{min}^{-1}$ and the column temperature was kept at $30^{\circ} \mathrm{C}$. Before penetrating into the column, the sample was kept at $7^{\circ} \mathrm{C}$. The recording of the mass spectra were performed on-line, on the collected fractions using an Orbitrap mass spectrometer (ThermoFisher, San Jose, CA) equipped with an ESI source in positive mode. The following ESI inlet conditions were used for the analysis: the capillary temperature was set to $380^{\circ} \mathrm{C}$, the pressure of the sheath gas to 47 PSI and the pressure of the auxilliary gas to 20 PSI. Mass spectra were recorded by using the doubly charged selected ion monitoring (DC-SIM) mode of the doubly charged ion peak 533.78 with a collision energy (CE) of $10 \%$.

\section{Results and discussion}

\section{Influence of the conditions used for the preparation of the copolymer layers on their structure.}

To prepare bifunctional copolymer layers presenting both free amino and thiol groups for subsequent functionalization, the P(DMA-co-TlaAm) copolymer was put in contact with gold surfaces in the presence of ethylenediamine. According to the reaction described in Scheme 2, the nucleophilic diamine derivative reacts with the thiolactone groups of the copolymer to form both thiol and amino pendant groups along the macromolecular chain. While a part of the released thiol groups is involved in the anchorage of the copolymer chains onto the gold surface, the remaining - $\mathrm{SH}$ groups are available, as well as the amino groups, to further immobilize compounds of interest onto the copolymer layer. However, a possible side reaction between two 
thiolactone groups and one diamine molecule, leading to the formation of crosslinks between the copolymer chains, can also occur. For this reason, the formation of the copolymer layer was investigated at two different concentrations, namely 0.2 and $2 \mathrm{mg} \cdot \mathrm{mL}^{-1}$. The obtained surfaces were analyzed by XPS to assess the influence of the copolymer concentration on their chemical composition. A surface modified with the P(DMA-co-TlaAm) copolymer in the presence of ethanolamine (i.e. mono-amine) was also characterized for the comparison (Table 1). The survey scans of all the samples showed $\mathrm{Au}, \mathrm{C}, \mathrm{N}, \mathrm{O}$ and $\mathrm{S}$ atoms as expected from their composition (as illustrated in Figure S1A for one sample, Supplementary Information). These results confirm the attachment of the aminolyzed copolymer chains onto the gold surface. Moreover, the XPS spectra measured with high energy resolution in the $S_{2 p}$ region can be decomposed in two peaks centered on $\sim 161.5$ and $\sim 164 \mathrm{eV}$ and corresponding to sulfur atoms anchored (S-Au) or not (S$\mathrm{H}$ and $\mathrm{S}-\mathrm{C}$ ) to the gold surface, respectively. The quantifications performed on the sulfur, nitrogen and gold peaks measured for copolymer layers grafted in the presence of ethylenediamine (Table 1), showed that a higher concentration of copolymer resulted in a higher nitrogen content, a much lower percentage of gold and a relative higher ratio of unbound sulfur atoms $\left((\mathrm{S}-\mathrm{H}+\mathrm{S}-\mathrm{C}) / \mathrm{S}_{\mathrm{tot}}\right)$, while the total amount of sulfur $\left(\mathrm{S}_{\mathrm{tot}}\right)$ remained unchanged. Interestingly, the comparison with a sample prepared with the same concentration of copolymer (i.e. $2 \mathrm{mg} \cdot \mathrm{mL}^{-1}$ ), but in the presence of ethanolamine, showed a lower attenuation of the gold signal. Altogether, these results suggest that thicker copolymer layers were grafted onto gold surfaces when the reaction was performed in the presence of diamine, in contrast with the formation of a monolayer when a mono-amine was used. 
Table 1. Atomic percentages of gold, nitrogen and sulfur measured by XPS for gold surfaces modified with P(DMA-co-TlaAm) layers prepared in different conditions.

\begin{tabular}{|c|c|c|c|c|c|c|c|}
\hline \multicolumn{2}{|c|}{$\begin{array}{l}\text { Conditions used } \\
\text { for the preparation } \\
\text { of the copolymer layer }\end{array}$} & \multicolumn{3}{|c|}{$\mathrm{S}$} & \multirow{2}{*}{$\begin{array}{c}(\mathrm{S}-\mathrm{C}+\mathrm{SH}) \\
/ \mathrm{S}_{\mathrm{tot}}(*)\end{array}$} & \multirow{2}{*}{$\begin{array}{c}\mathrm{N} \\
(\%)\end{array}$} & \multirow{2}{*}{$\begin{array}{l}\mathrm{Au} \\
(\%)\end{array}$} \\
\hline $\begin{array}{l}\text { Copolymer } \\
\text { concentration } \\
\left(\mathrm{mg} \cdot \mathrm{mL}^{-1}\right)\end{array}$ & $\begin{array}{l}\text { Amine } \\
\text { derivative }\end{array}$ & $\begin{array}{l}\mathrm{S}- \\
\mathrm{Au}^{(*)} \\
(\%)\end{array}$ & $\begin{array}{c}\mathrm{S}-\mathrm{C}+\mathrm{S}-\mathrm{H}^{(*)} \\
(\%)\end{array}$ & $\begin{array}{c}\mathrm{S}_{\mathrm{tot}}(*) \\
(\%)\end{array}$ & & & \\
\hline 0.2 & Ethylenediamine & 0.8 & 2.0 & 2.8 & 0.71 & 10.1 & 13.9 \\
\hline 2 & Ethylenediamine & 0.4 & 2.4 & 2.8 & 0.86 & 12.5 & 0.2 \\
\hline 2 & Ethanolamine & 1.2 & 1.0 & 2.2 & 0.45 & 7.8 & 20.3 \\
\hline
\end{tabular}

(*) S-Au correspond to the thiol groups anchored on the gold surface, S-C and S-H to the thiol groups which are not anchored to the gold surface and $S_{\text {tot }}$ to the total amount of thiol groups in the copolymer layer.

To check this point, AFM measurements were performed on samples prepared in different conditions (Figure 1). The surfaces prepared using copolymer and ethanolamine showed a morphology close to the bare gold surface (Figure 1A). The average roughness of bare gold and gold surface covered with a copolymer grafted in the presence of ethanolamine was $1.1 \pm 0.1$ and $1.4 \pm 0.1 \mathrm{~nm}$, respectively. The unchanged morphology and the similar roughness attest for the deposition of a thin monolayer of copolymer onto gold surface in the presence of ethanolamine. By contrast, the surfaces prepared in the presence of ethylenediamine showed copolymer aggregates whose size increased with the copolymer concentration (Figures 1B and 1C). 

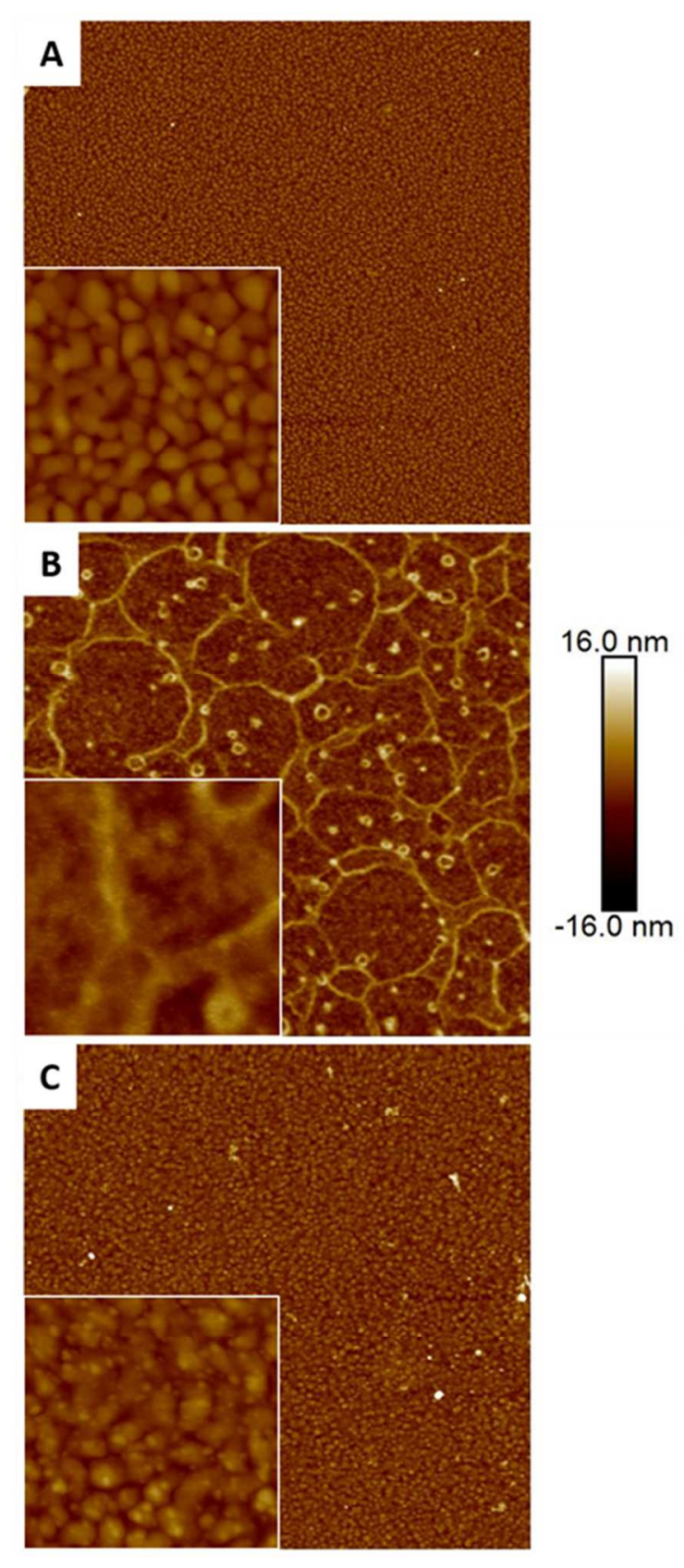

Figure 1. 5 x $5 \mu \mathrm{m}^{2}$ AFM images of gold surfaces modified with copolymer layers prepared in different conditions: with a $2 \mathrm{mg} \cdot \mathrm{mL}^{-1}$ copolymer solution in the presence of ethanolamine (A); with $2 \mathrm{mg} \cdot \mathrm{mL}^{-1} \quad$ (B) and $0.2 \mathrm{mg} \cdot \mathrm{mL}^{-1}$ (C) copolymer solutions in the presence of ethylenediamine. Insets show $0.5 \times 0.5 \mu \mathrm{m}^{2}$ zoom-in images. 
The average roughness measured for the surfaces prepared with 0.2 and $2 \mathrm{mg} \cdot \mathrm{mL}^{-1}$ copolymer solutions is $1.4 \pm 0.1$ and $2.1 \pm 0.6 \mathrm{~nm}$, respectively. The roughness of the surface prepared with the lower copolymer concentration is similar to the one measured for surfaces functionalized in the presence of ethanolamine. Therefore, these results confirmed that the copolymer layers prepared in the presence of diamine are composed of aggregates that come from the side crosslinking reaction occurring during the aminolysis process, between the diamine derivative and the thiolactone rings of the copolymer, especially when a higher concentration of copolymer is used.

\section{Modification of the pendent amine groups of the copolymer layers.}

The modification of the free amino groups present in the copolymer layers prepared with ethylenediamine was tested by using two different carboxylic acid derivatives (Scheme 3, modification sequence A, step 1). First a fluorescent bioadhesive peptide (RGD-FITC) preactivated by EDC/sulfo-NHS, was put in contact with the copolymer layer. Two different copolymer layers prepared with $0.2 \mathrm{mg} \cdot \mathrm{mL}^{-1}$ and $2 \mathrm{mg} \cdot \mathrm{mL}^{-1}$ copolymer solutions were used for this test. The inspection of the resulting surfaces by fluorescence microscopy evidenced the presence of the FITC-labeled peptide on both samples but also heterogeneities that are larger and more fluorescent on the sample prepared with a higher copolymer concentration (Figure 2). 

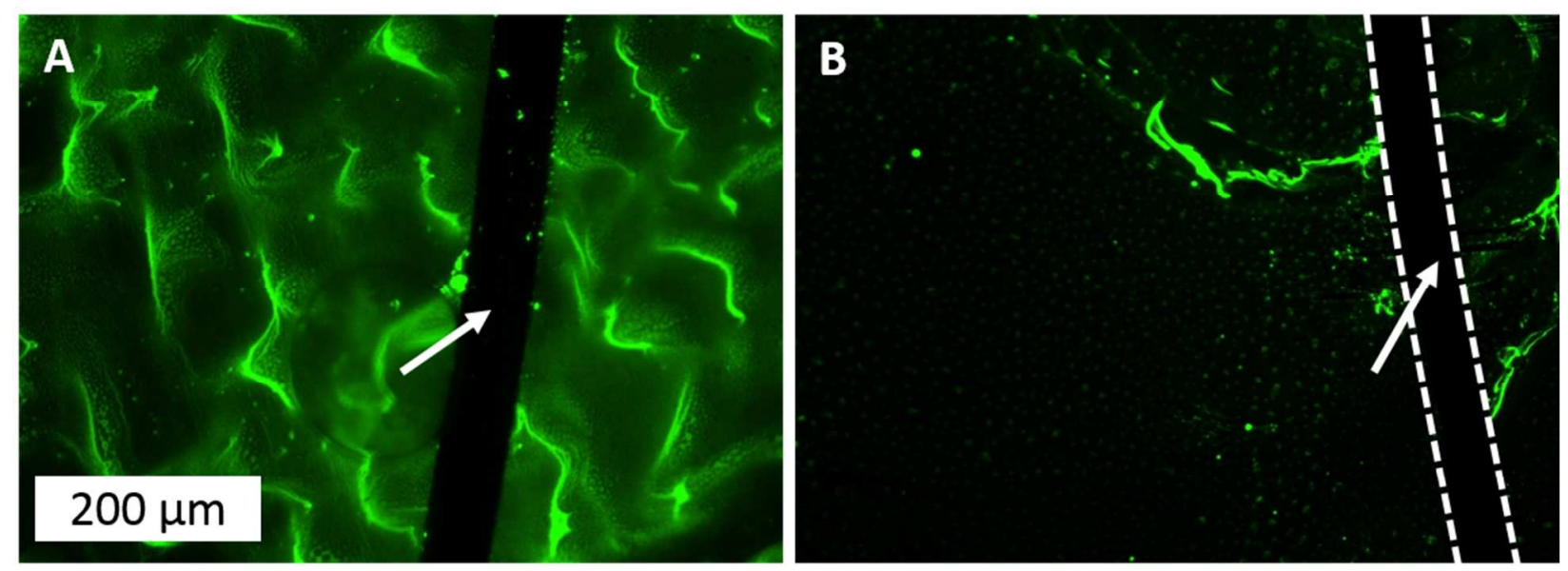

Figure 2. Fluorescence images of gold surfaces modified with a copolymer layer prepared in the presence of ethylenediamine then grafted with a RGD-FITC peptide: copolymer layer prepared using $2 \mathrm{mg} \cdot \mathrm{mL}^{-1}$ (A) and $0.2 \mathrm{mg} \cdot \mathrm{mL}^{-1}$ (B) copolymer solutions. The exposition time used to record the images was $1 \mathrm{sec}$ and $5 \mathrm{sec}$ for images (A) and (B), respectively. A deliberate scratch (black line, indicated by a white arrow) was made on each surface to show the fluorescence difference between the uncovered background and the grafted layer.

Similar tests performed with non-preactivated RGD-FITC peptide did not provide fluorescence (result not shown). Therefore, it can be concluded that the fluorescence signal observed after addition of the preactivated peptide onto the modified surfaces was due to the covalent grafting of the peptide molecules on the free amino groups of the copolymer layer and not to the adsorption of the peptide molecules on the copolymer layer or on the gold surface. The heterogenities observed on the grafed surfaces result from the intrinsic agregated structure of the copolymer layers, as evidenced by AFM at a smaller scale (Figure 1). Moreover, the higher fluorescence intensity observed for the surface modified with a more concentrated copolymer solution, is in agreement with the presence of larger copolymer aggregates rich in free amino groups (Figure 1 and Table 1). 
To evaluate more quantitatively the amount of carboxylic acid derivative that can be grafted on the copolymer layers, trifluorobutyric acid molecules containing fluorine atoms easily detected by XPS, were grafted on a copolymer layer via the EDC/sulfo-NHS coupling. This test was performed only on a thick copolymer layer prepared with a $2 \mathrm{mg} \cdot \mathrm{mL}^{-1}$ copolymer solution. Indeed, in these conditions, the gold substrate is only poorly seen by XPS (Table 1), so that the measured signals essentially relates to the bulk composition of the modified copolymer layer. XPS measurements performed on this layer (Supporting Information, Figure S1B) revealed the presence of an additional fluorine signal as expected. To estimate the grafting degree on the amino groups of the copolymer layer, XPS spectra were recorded with high energy resolution in the $S_{2 p}$ and $F_{1 s}$ regions. It was determined from these measurements that about 23 trifluorobutyric acid molecules were grafted for 100 thiolactone units. While this grafting degree is quite limited, it is worth noting that a part of the amino groups released during the grafting of the copolymer layer on gold surface were involved in crosslinks due to the side reaction occurring at the same time. Therefore, the amount of free amino groups effectively present in the copolymer layers and available for the immobilization of a carboxylic derivative, is lower than expected when considering the composition of the copolymer.

\section{Grafting and release of a thiolated compound on the free thiol groups of the copolymer layers.}

Besides the presence of amine groups in the copolymer layers, the free thiol groups distributed along the copolymer chains, offer the possibility to reversibly graft thiolated compounds through a disulfide link. Indeed, such a link can be easily cleaved under mild reductive conditions to release the grafted compound on demand. To test this approach, the grafting and the subsequent release of PEG-SH (used as a model thiolated molecule) on the copolymer layers was studied. 
For this, thicker layers prepared with a $2 \mathrm{mg} \cdot \mathrm{mL}^{-1}$ copolymer in the presence of ethylenediamine, were first exposed to a PEG-SH solution in the presence of CaT, to get oxidative conditions required for the formation of the disulfide link. In a second step, the modified surfaces were immersed in a reducing medium to operate the release of the PEG-SH molecules through the cleavage of disulfide bonds between the thiol groups of the copolymer and the PEG-SH model molecules. Two different reducing solutions containing DTT or L-glutathione were tested for this last step. Impedance measurements were performed after each step to detect changes at the Au-solution interface. The $\mathrm{R}_{\mathrm{ct}}$ values were computed by modelling the Nyquist plots with a Randles equivalent circuit and an estimation of the coverage of the surface, directly related to $R_{c t}$, was also calculated (Eq. 1). Nyquist plots as well as the $R_{c t}$ and surface coverage values measured after each surface treatment are displayed in Figure 3. The comparison of Nyquist plots obtained for a gold surface modified by the copolymer (Figure 3, curves 2) and the same surface treated by a PEG-SH solution in oxidizing condition (Figure 3, curves 3) evidenced the grafting of PEG molecules on the copolymer layer. As a result, significant increases of $R_{c t}$ (from 40 to $104 \mathrm{k} \Omega$ in Figure 3B and from 18 to $69 \mathrm{k} \Omega$ Figure 3D) and surface coverage (Figures 3B and 3D) are observed. Altogether these results prove the successful grafting of PEG-SH molecules on the copolymer layer. ${ }^{44}$ In contrast, significant decreases of $\mathrm{R}_{\mathrm{ct}}$ (decrease of 46 and $20 \mathrm{k} \Omega$ in Figures 3B and 3D, respectively) and surface coverage were observed when the surfaces were immersed in reducing solutions of DTT (Figure 3B) or L-glutathione (Figure 3D). In both cases, these results demonstrated the successful release of PEG-SH molecules from the copolymer layers due to the cleavage of disulfide links. However, the release of thiolated compound was more pronounced when the surfaces were exposed to DTT (see difference between curves 3 and 4 in Figure 3A) compared to L-glutathione (see difference between curves 
3 and 4 in Figure 3C), even if the DTT concentration $(2 \mathrm{mM})$ used for these tests was much lower than the L-glutathione one $(10 \mathrm{mM})$. The stronger ability of DTT to cleave disulfide links compared to L-glutathione is explained by its stronger reducing power. ${ }^{46}$
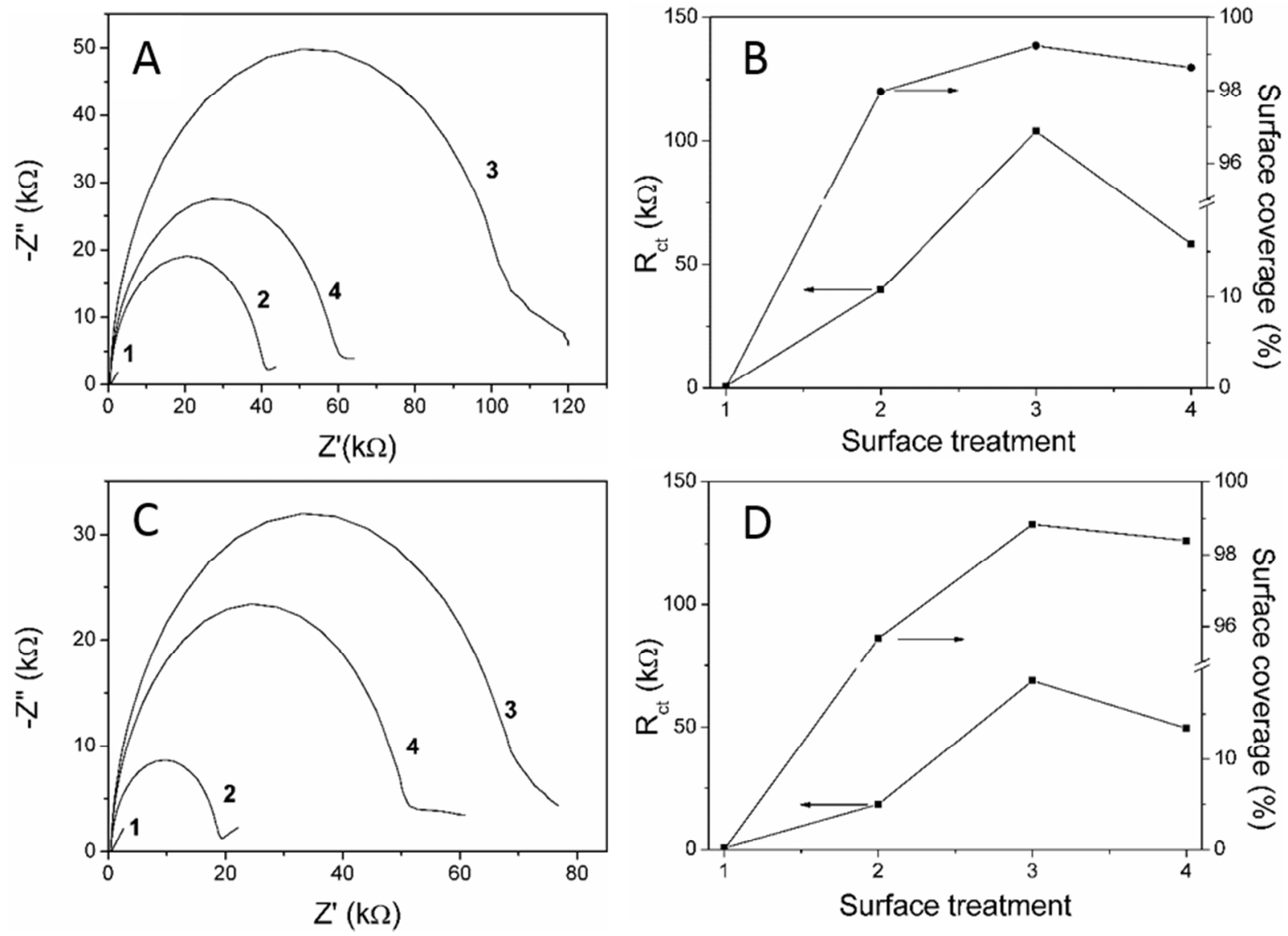

Figure 3. (A-C) Nyquist plots traced from EIS measurements. (B-D) $R_{c t}$ and surface coverage values estimated after each surface treatment, by fitting the values of the Nyquist plot with a Randles equivalent circuit. Measurements were performed on bare gold electrode (reference surface) (1), then on electrode modified with a copolymer layer formed in the presence of ethylenediamine (2), subsequently treated with PEG-SH in the presence of CaT (3), and finally exposed to a reducing medium (4) which is DTT (A and B) or L-glutathione (C and D). 
Though the release of PEG-SH was not fully achieved when using both reducing agents (the EIS response measured after the reducing treatment could not superpose with the initial EIS response measured prior to PEG-SH grafting; see the non-superposition of curves 2 and 4 in Figures 3A and $3 \mathrm{C}$ ), the fact that a large part of thiolated compound could be released in the presence of a biocompatible reducing agent (i.e. L-glutathione) is promising for potential biological applications of these layers. While the general grafting/release of the thiolated PEG under redox stimulation was clearly evidenced (Figure 3), it is worth noting that a large variation of absolute $R_{\mathrm{ct}}$ values was observed from sample to sample after grafting the copolymer layer onto the gold surface (see difference of $\mathrm{R}_{\mathrm{ct}}$ values displayed in Figures 3B and 3D for surface treatment 2) and consequently, after grafting the thiolated compound (see difference of $R_{c t}$ values displayed in Figures $3 \mathrm{~B}$ and $3 \mathrm{D}$ for surface treatment 3 ). This variation between the samples can be attributed to two phenomena. First, the uncontrolled crosslinking reaction occurring during the aminolysis process in the presence of the diamine results in a poor control of the amount of polymer immobilized onto the gold surface. Indeed, the size of the crosslinked copolymer aggregates grafted onto the surface slightly varied from sample to sample resulting in variation of EIS response. Second, copolymer layers prepared in the presence of a diamine present positively charged amino groups $\left(-\mathrm{NH}_{3}{ }^{+}\right)$, while neutral layers were obtained when using ethanolamine. ${ }^{44}$ Yet, the $\mathrm{R}_{\mathrm{ct}}$ values not only depend on the alteration of the resistance generated by the grafting (or release) of passivating compounds on the surface but, also on the presence of ionic charges on the surface, which can interfere with the negatively charged redox probe. ${ }^{46,49}$ So, in the present study, the EIS results qualitatively proved the successful grafting and release of the PEGSH compound but did not allow for quantitative analysis. 


\section{Sequential modification of amine and thiol groups present in the copolymer layers.}

After having evidenced the possibility to modify separately amine and thiol groups present in the copolymer layers, we studied the successive modification of both chemical groups to prepare bifunctionalized layers showing redox-responsive properties. For this purpose, two different sequences of modification of the copolymer layers were tested (Scheme 3): the amino groups were modified first and subsequently the thiol groups (sequence A) or the reverse (sequence B). To estimate the influence of the grafting sequence on the amount of thiolated derivative immobilized on free thiol groups of the copolymer layer, fluorescent Rhod B-PEG-SH was used. The images recorded by epifluorescence microscopy for copolymer layers bifunctionalized with glycylglycine and Rhod B-PEG-SH according to the sequences A and B (Scheme 3) were analyzed and the relative fluorescence intensities measured for these surfaces are shown in Figure 4. The value obtained for a copolymer layer modified with Rhod B-PEG-SH only was also added for comparison. Both bifunctionalized layers showed fluorescence of similar intensity, demonstrating the successful grafting of Rhod B-PEG-SH regardless of the modification sequence (A or B). However, the fluorescence intensity measured on these bifunctionalized surfaces was divided by a factor of two compared to the monofunctionalized copolymer layer grafted with Rhod B-PEG-SH only. This indicates that the EDC/sulfo-NHS treatment performed to graft glycylglycine on amino groups of the copolymer layer impacted the grafting of the thiolated derivative on the thiol groups, independently of the grafting sequence used. It seems that this chemical treatment most likely de-activated a part of free thiol groups present in the copolymer layer during the first step (Scheme 3, step 1) of the grafting sequence A but also cleaved some disulfide links formed during the first step (Scheme 3, step 1') of the grafting sequence B. 


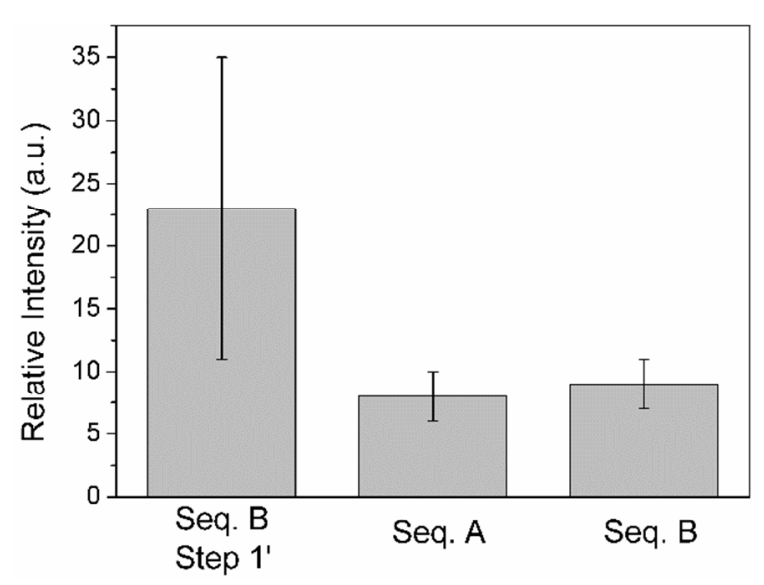

Figure 4. Relative fluorescence intensity measured for bifunctionalized copolymer layers prepared with a $2 \mathrm{mg} / \mathrm{mL}$ copolymer solution in the presence of ethylenediamine, which have then be grafted with Rhod B-PEG-SH and glycylglycine, according to the grafting sequence A or B described in the Scheme 3. The average intensity value measured for a copolymer layer modified only with Rhod B-PEG-SH (Seq. B, step 1') was added for comparison.

The preparation of a bifunctionalized copolymer layer according to the grafting sequence A was followed by EIS (Figure 5). The Nyquist plots revealed a clear increase of $\mathrm{R}_{\mathrm{ct}}$ (from 49 to $110 \mathrm{k} \Omega$ ) and surface coverage after the grafting of PEG-SH on free thiol groups of a copolymer layer pre-modified with glycylglycine (Figure 5B). This result is in agreement with epifluorescence microscopy measurements (Figure 4), showing that some free thiol groups were still available in the copolymer layer after the modification of the amine groups and could be successfully used to immobilize a thiolated derivative. Moreover, the treatment of such a bifunctionalized surface by DTT (Figure 5, surface treatment 4) or L-glutathione (results not shown) induced a strong decrease of $\mathrm{R}_{\mathrm{ct}}$ due to the release of PEG-SH molecules. Altogether, the EIS experiments prove that bifunctionalized layers show redox-responsive properties, allowing the release of a compound of interest on demand. 

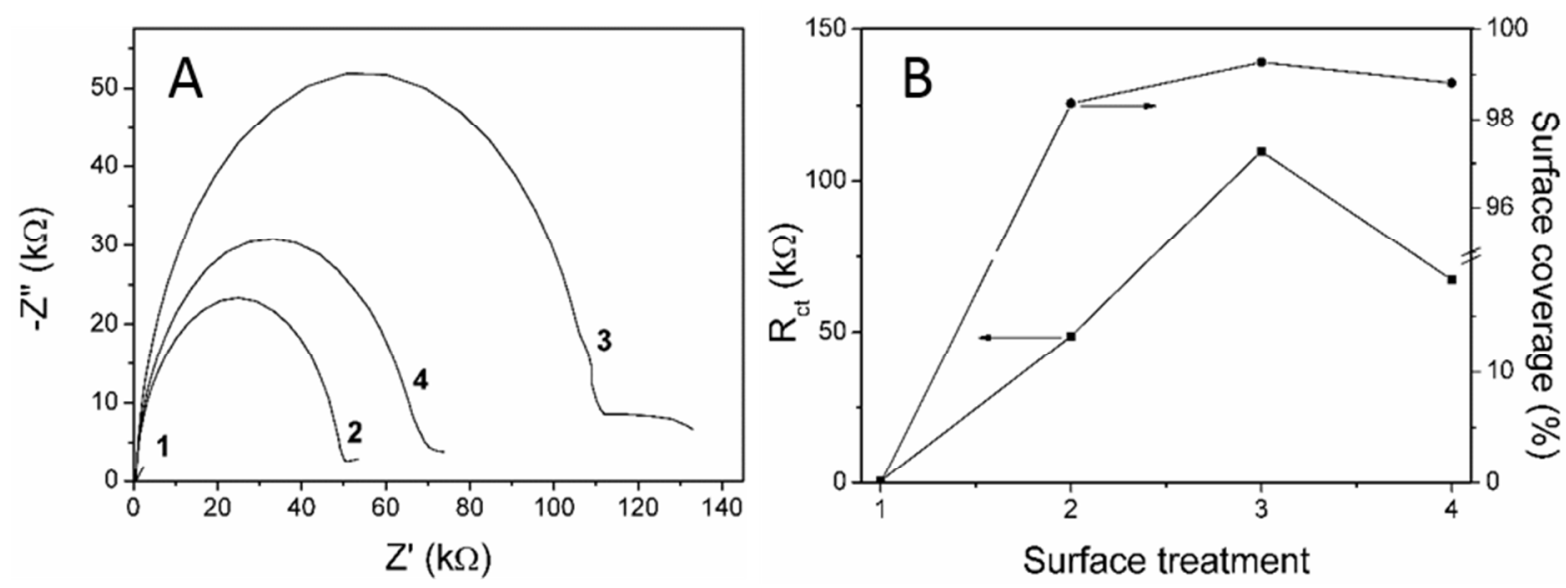

Figure 5. (A) Nyquist plots of EIS. (B) $R_{c t}$ and surface coverage values estimated after each surface treatment, by fitting the values of the Nyquist plot with a Randles equivalent circuit. Measurements were performed on bare gold electrode (reference surface) (1), then on the same electrode modified with a copolymer layer formed in the presence of ethylenediamine and grafted with glycylglycine on amino groups according to the sequence A described in the Scheme 3 (2), subsequently treated with PEG-SH in the presence of CaT (3), and finally exposed to DTT (4).

Next, to quantify the ability of bifunctionalized copolymer layers to release a compound of interest under redox stimulation, an OVA peptide incorporating a cysteine unit and used as a model molecule, was grafted on free thiol groups of a copolymer layer pre-modified with glycylglycine (Scheme 3, sequence A, step 2). The resulting surface was treated by DTT and the composition of the supernatant was characterized by HPLC-MS. It was measured that $0.02 \pm 0.01 \mathrm{ng}$ of OVA peptide was released per $\mathrm{mm}^{2}$ of treated surface, which corresponds to $0.011 \pm 0.006$ molecules per $\mathrm{nm}^{2}$. A high variability (of about 50\%) was observed, demonstrating by other means than EIS, that the amount of copolymer grafted on the gold 
surface is poorly reproducible from one surface to another one, because of the crosslinking reaction occurring during the preparation of the copolymer layer. A similar test was performed by grafting then releasing OVA peptide on a non pre-modified copolymer layer prepared in the presence of ethylenediamine (Scheme 3, sequence B, step 1'). A value of $0.025 \pm 0.001$ molecules per $\mathrm{nm}^{2}$ was obtained. These results are in agreement with the epifluorescence microscopy quantifications displayed in Figure 3 which evidenced that a higher amount of thiolated compound is immobilized on a copolymer layer whose amine groups are not grafted compared to a pre-modified layer. For comparison, Deschaume et al. prepared SAMs of amineterminated silanes to graft different peptides and proteins. ${ }^{50}$ Among others, a RGD peptide with 7 amino-acids was grafted on these surfaces, via a 3-succinimidyl-3-maleimidopropionate linker, and a density of 0.42 molecules per nm was obtained. The higher value of peptide density observed in this study compared to our case, may be due to the fact that SAMs layers present a much higher amount of functional groups per surface unit compared to the copolymer layer used in our approach. The bifunctionalized layers developed in this study could therefore be used for applications in which the compound of interest does not need to be grafted with a high surface density, such as enzyme-functionalized surfaces used in biocatalysis, for instance.

\section{Conclusion}

Thin macromolecular layers containing both free amine and thiol groups were successfully grafted on gold surfaces in a one-step procedure, using a thiolactone-based copolymer as stable precursor. The obtained layers were further bifunctionalized through reactions of their free amine and thiol groups with carboxylic acid and thiolated derivatives, respectively. Finally, the release of thiolated derivatives immobilized on these macromolecular layers through disulfide bond 
cleavage under mild reducing conditions was demonstrated, proving the redox-responsiveness of these layers. Such bifunctional layers can be advantageously developed to produce bioactive surfaces presenting two active components at the same time, such as enzyme and substrate or bioadhesive peptide and growth factor or antibacterial peptide. Moreover, the possibility to release one of the components on demand, under biocompatible conditions, offers the opportunity to control biological processes such as an enzymatic reaction or a cellular mechanism such as differentiation or apoptosis for animal cells or cellular killing for microorganisms.

\section{ASSOCIATED CONTENT}

Supporting Information. The following files are available free of charge. XPS survey scan measured for a copolymer layer prepared in the presence of diamine on gold substrate and grafted with trifluorobutyric acid (Figure S1).

\section{AUTHOR INFORMATION}

Corresponding Authors

*Email: sophie.demoustier@uclouvain.be; karine.glinel@uclouvain.be

\section{Present Address}

† S. Belbekhouche: Université Paris Est, ICMPE (UMR7182), CNRS, UPEC, F-94320 Thiais, France

\section{Author Contributions}

The manuscript was written through contributions of all authors. All authors have given approval to the final version of the manuscript. 


\section{ACKNOWLEDGEMENTS}

This work was supported by the Belgian Federal Science Policy (IAP program P7/05). Pierre Eloy and Cécile d'Haese are thanked for their help with XPS and AFM measurements. Diana Ramirez and Raoul Rozenberg are acknowledged for their help with HPLC-MS measurements. CC benefits from a FRIA research fellowship provided by the F.R.S.-FNRS. KG is a Research Associate of the F.R.S.-FNRS.

\section{REFERENCES}

1. Love, J. C.; Estroff, L. A.; Kriebel, J. K.; Nuzzo, R. G.; Whitesides, G. M. SelfAssembled Monolayers of Thiolates on Metals as a Form of Nanotechnology. Chem. Rev. 2005, 105, 1103-1169.

2. Draper, M. C.; Crick, C. R.; Orlickaite, V.; Turek, V. A.; Parkin, I. P.; Edel, J. B. Superhydrophobic Surfaces as an On-Chip Microfluidic Toolkit for Total Droplet Control. Anal. Chem. 2013, 85, 5405-5410.

3. Wildling, L.; Unterauer, B.; Zhu, R.; Rupprecht, A.; Haselgrübler, T.; Rankl, C.; Ebner, A.; Vater, D.; Pollheimer, P.; Pohl, E. E.; Hinterdorfer, P.; Gruber, H.J. Linking of sensor molecules with amino groups to amino-functionalized AFM tips. Bioconjugate Chem. 2011, 22, 1239-1248.

4. Barbosa, O.; Torres, R.; Ortiz, C.; Berenguer-Murcia, Á.; Rodrigues, R. C.; FernandezLafuente, R. Heterofunctional supports in enzyme immobilization: From traditional immobilization protocols to opportunities in tuning enzyme properties. Biomacromolecules. 2013, 14, 2433-2462.

5. Gray, C. J.; Weissenborn, M. J.; Eyers, C. E.; Flitsch, S. L. Enzymatic reactions on immobilised substrates. Chem. Soc. Rev. 2013, 42, 6378-6405.

6. Fernandes, A. E.; Riant, O.; Jonas, A. M.; Jensen, K. F. One "Click" to controlled 
bifunctional supported catalysts for the $\mathrm{Cu}$ /TEMPO-catalyzed aerobic oxidation of alcohols. $R S C A d v$. 2016, 6, 36602-36605.

7. Min, K.; Yoo, Y. J. Recent progress in nanobiocatalysis for enzyme immobilization and its application. Biotechnol. Bioprocess Eng. 2014, 19, 553-567.

8. Hersel, U.; Dahmen, C.; Kessler, H. RGD modified polymers: Biomaterials for stimulated cell adhesion and beyond. Biomaterials 2003, 24, 4385-4415.

9. Perlin, L.; MacNeil, S.; Rimmer, S. Production and performance of biomaterials containing RGD peptides. Soft Matter 2008, 4, 2331-2349.

10. Zouani, O. F.; Chollet, C.; Guillotin, B.; Durrieu, M. C. Differentiation of pre-osteoblast cells on poly(ethylene terephthalate) grafted with RGD and/or BMPs mimetic peptides. Biomaterials 2010, 31, 8245-8253.

11. Yu, Q.; Wu, Z.; Chen, H. Dual-function antibacterial surfaces for biomedical applications. Acta Biomater. 2015, 16, 1-13.

12. Glinel, K.; Jonas, A. M.; Jouenne, T.; Galas, L.; Huck, W. T. S. Antibacterial and Antifouling Polymer Brushes Incorporating Antimicrobial Peptide. Bioconjugate Chem. 2009, 20, 71-77.

13. Thebault, P.; Taffin de Givenchy, E.; Guittard, F.; Guimon, C.; Géribaldi, S. Selfassembled monolayers of semi-fluorinated thiols and disulfides with a potentially antibacterial terminal fragment on gold surfaces. Thin Solid Films 2008, 516, 1765-1772.

14. Carvalho, A. L.; Vale, A. C.; Sousa, M. P.; Barbosa, A. M.; Torrado, E.; Mano, J. F. Antibacterial bioadhesive layer-by-layer coatings for orthopedic applications. J. Mater. Chem. B 2016, 4, 5385-5393.

15. Palchesko, R. N.; Buckholtz, G. A.; Romeo, J. D.; Gawalt, E. S. Co-immobilization of active antibiotics and cell adhesion peptides on calcium based biomaterials. Mater. Sci. Eng. C 2014, 40, 398-406. 
16. Godjevargova, T.; Dayal, R.; Marinov, I. Simultaneous covalent immobilization of glucose oxidase and catalase onto chemically modified acrylonitrile copolymer membranes. J. Appl. Polym. Sci. 2004, 91, 4057-4063.

17. Fernandes, A. E.; Riant, O.; Jensen, K. F.; Jonas, A. M. Molecular Engineering of Trifunctional Supported Catalysts for the Aerobic Oxidation of Alcohols. Angew. Chem., Int. Ed. 2016, 55, 11044-11048.

18. Goddard, J. M.; Hotchkiss, J. H. Polymer surface modification for the attachment of bioactive compounds. Prog. Polym. Sci. 2007, 32, 698-725.

19. Ferretti, S.; Paynter, S.; Russell, D. A.; Sapsford, K. E.; Richardson, D. J. Self-assembled monolayers: a versatile tool for the formulation of bio-surfaces. TrAC Trends Anal. Chem. 2000, 19, 530-540.

20. Wong, L. S.; Khan, F.; Micklefield, J. Selective covalent protein immobilization: Strategies and applications. Chem. Rev. 2009, 109, 4025-4053.

21. Gooding, J. J.; Ciampi, S. The molecular level modification of surfaces: from selfassembled monolayers to complex molecular assemblies. Chem. Soc. Rev. 2011, 40, 27042718.

22. Mahapatro, A. Bio-functional nano-coatings on metallic biomaterials. Mater. Sci. Eng. C. 2015, 55, 227-251.

23. Kind, M.; Wöll, C. Organic surfaces exposed by self-assembled organothiol monolayers: Preparation, characterization, and application. Prog. Surf. Sci. 2009, 84, 230-278.

24. Feng, J.; Xu, G. H.; An, Y.; Zeng, X. Construction of the homogeneously mixed SAM composed of octyltriethoxysilane and octadecyltrichlorosilane by taking advantage of the molecular steric restriction. Colloids Surf. A 2008, 316, 194-201.

25. Folkers, J. P.; Laibinis, P.E.; Whitesides, G. M. Self-assembled monolayers of alkanethiols on gold: the adsorption and wetting properties of monolayers derived from two components with alkane chains of different lengths. J. Adhes. Sci. Technol. 1992, 6, 
1397-1410.

26. Laibinis, P. E.; Nuzzo, R. G.; Whitesides, G. M. Structure of monolayers formed by coadsorption of two n-alkanethiols of different chain lengths on gold and its relation to wetting. J. Phys. Chem. 1992, 96, 5097-5105.

27. Mani, G.; Johnson, D.M.; Marton, D.; Feldman, M. D.; Patel, D.; Ayon, A. A.; Agrawal, C. M. Drug delivery from gold and titanium surfaces using self-assembled monolayers. Biomaterials 2008, 29, 4561-4573.

28. Das, M.; Shim K. H.; An, S. S. A.; Yi D. K. Review on gold nanoparticles and their applications. J. Toxicol. Environ. Health Sci. 2011, 3, 193-205.

29. Dijksma, M.; Kamp, B.; Hoogvliet, J. C.; Van Bennekom, W. P.; Formation and electrochemical characterization of self-assembled monolayers of thioctic acid on polycrystalline gold electrodes in phosphate buffer pH 7.4. Langmuir 2000, 16, 38523857.

30. Mrksich, M.; Whitesides, G. M. Patterning self-assembled monolayers using microcontact printing: A new technology for biosensors? Trends Biotechnol. 1995, 13, 228-235.

31. Srisombat, L.; Jamison, A. C.; Lee, T. R. Stability: A key issue for self-assembled monolayers on gold as thin-film coatings and nanoparticle protectants. Colloids Surfaces A Physicochem. Eng. Asp. 2011, 390, 1-19.

32. Rouhana, L. L.; Moussallem, M. D.; Schlenoff, J. B. Adsorption of short-chain thiols and disulfides onto gold under defined mass transport conditions: coverage, kinetics, and mechanism. J. Am. Chem. Soc. 2011, 133, 16080-16091.

33. Vericat, C.; Vela, M. E.; Salvarezza, R. C. Self-assembled monolayers of alkanethiols on Au (111): surface structures, defects and dynamics. Phys. Chem. Chem. Phys. 2005, 7, 3258-3268.

34. Farah, A. A.; Zheng, S. H.; Morin, S.; Bensebaa, F.; Pietro, W. J. Thiolated poly( $\varepsilon^{-}$ caprolactone) macroligand with vacant coordination sites on gold substrate: Synthesis and 
surface characterization. Surf. Sci. 2007, 601, 1677-1683.

35. Le Neindre, M.; Nicolaÿ, R.; Polythiol copolymers with precise architectures: a platform for functional materials. Polym. Chem. 2014, 5, 4601-4611.

36. Stamenovic, M. M.; Espeel, P.; Baba, E.; Yamamoto, T.; Tezuka, Y.; Du Prez, F. E. Straightforward synthesis of functionalized cyclic polymers in high yield via RAFT and thiolactone-disulfide chemistry. Polym. Chem. 2013, 4, 184-193.

37. Reinicke, S.; Espeel, P.; Stamenović, M. M.; Du Prez, F. E. One-Pot Double Modification of p(NIPAAm): A Tool for Designing Tailor-Made Multiresponsive Polymers. ACS Macro Lett. 2013, 2, 539-543.

38. Espeel, P.; Goethals, F.; Du Prez, F. E. One-Pot Multistep Reactions Based on Thiolactones: Extending the Realm of Thiol-Ene Chemistry in Polymer Synthesis. J. Am. Chem. Soc. 2011, 133, 1678-1681.

39. Reinicke, S.; Espeel, P.; Stamenović, M. M.; Du Prez, F. E. Synthesis of multifunctionalized hydrogels by a thiolactone-based synthetic protocol. Polym. Chem. 2014; 5 , 5461-5470.

40. Espeel, P.; Goethals, F.; Stamenovic, M. M.; Petton, L.; Du Prez, F. E. Double modular modification of thiolactone-containing polymers: towards polythiols and derived structures. Polym. Chem. 2012, 3, 1007-1015.

41. Espeel, P.; Du Prez, F. E. One-pot multi-step reactions based on thiolactone chemistry: A powerful synthetic tool in polymer science. Eur. Polym. J. 2015, 62, 247-272.

42. Goethals, F.; Frank, D.; Du Prez, F.E. Protected thiol strategies in macromolecular design. Prog. Polym. Sci. 2017, 64, 76-113.

43. Reinicke, S.; Rees, H.C.; Espeel, P.; Vanparijs, N.; Bisterfeld, C.; Dick, M.; Rosencrantz, R.R.; Brezesinski, G.; de Geest, B.G.; Du Prez, F.E.; Pietruszka, J.; Böker, A. Immobilization of 2-Deoxy-D-ribose-5-phosphate Aldolase in Polymeric Thin Films via the Langmuir-Schaefer Technique. ACS Appl. Mater. Interfaces 2017, 9, 8317-8326. 
44. Belbekhouche, S.; Reinicke, S.; Espeel, P.; Du Prez, F. E.; Dupont-Gillain, C.; Jonas, A. M.; Demoustier-Champagne, S.; Glinel, K. Polythiolactone-based redox-responsive layers for the reversible release of functional molecules. ACS Appl. Mater. Interfaces 2014, 6, 22457-22466.

45. K'Owino, I. O.; Sadik, O. A. Impedance Spectroscopy: A Powerful Tool for Rapid Biomolecular Screening and Cell Culture Monitoring. Electroanalysis 2005, 17, 21012113.

46. Wallen, R.; Gokarn, N.; Bercea, P.; Grzincic, E.; Bandyopadhyay, K. Mediated Electron Transfer at Vertically Aligned Single-Walled Carbon Nanotube Electrodes During Detection of DNA Hybridization. Nanoscale Res. Lett. 2015, 10, 268-278.

47. Ribaut, C.; Reybier, K.; Torbiero, B.; Launay, J.; Valentin, A.; Reynes, O.; Fabre, P. L.; Nepveu, F. Strategy of red blood cells immobilisation onto a gold electrode: Characterization by electrochemical impedance spectroscopy and quartz crystal microbalance. IRBM 2008, 29, 141-148.

48. Rothwarf, D. M.; Scheraga, H. Equilibrium and kinetic constants for the thiol-disulfide interchange reaction between glutathione and dithiothreitol. Proc. Natl. Acad. Sci. U. S. A. 1992, 89, 7944-7948.

49. Fernandes, D. M.; Ghica, M. E.; Cavaleiro, A. M. V.; Brett, C. M. A. Electrochemical impedance study of self-assembled layer-by-layer iron-silicotungstate/poly(ethylenimine) modified electrodes. Electrochim. Acta 2011, 56, 7940-7945.

50. Deschaume, O.; Magnin, D.; Cheng, Z. A.; Douchamps, C.; Labbé, P., Yunus, S., Durrieu, M.; Nysten, B.; Glinel, K.; Demoustier-Champagne, S.; Jonas, A. M. Comparison of the density of proteins and peptides grafted on silane layers and polyelectrolyte multilayers. Biomacromolecules, 2014, 15, 3706-3716. 
Synopsis TOC

1

2

3

5

6

6

7
8

8

10

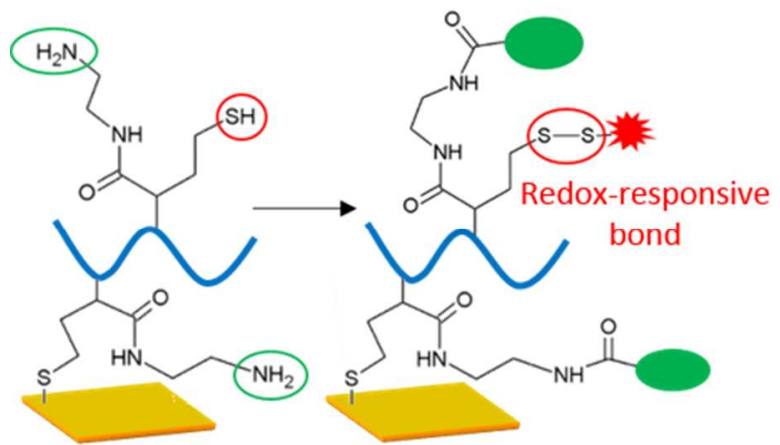

